D.O.I.: $10.3895 / \mathrm{S} 1808-04482009000200011$

\title{
A IMPORTÂNCIA DOS PROCESSOS DE APRENDIZAGEM PARA ACUMULAÇÃO DE COMPETÊNCIAS TECNOLÓGICAS: UM ESTUDO DE CASO (1999 - 2008)
}

\section{THE IMPORTANCE OF LEARNING PROCESSES TO ACCUMULATE TECHNOLOGICAL COMPETENCES: A CASE STUDY (1999 - 2008)}

\author{
Lucyanno Moreira Cardoso de Holanda ${ }^{1}$; Neudi Luís Scandolara ${ }^{2}$; Antonio Carlos de Francisco ${ }^{3}$ \\ ${ }^{1}$ Universidade Tecnológica Federal do Paraná - UTFPR - Ponta Grossa - Brasil \\ lucyanno@gmail.com \\ ${ }^{2}$ Universidade Tecnológica Federal do Paraná - UTFPR - Ponta Grossa - Brasil \\ neudi.scandolara@masisa.com \\ ${ }^{3}$ Universidade Tecnológica Federal do Paraná - UTFPR - Ponta Grossa - Brasil \\ acfrancisco@utfpr.edu.br
}

\begin{abstract}
RESUMO: O presente artigo tem como objetivo analisar como a aprendizagem organizacional influenciou na acumulação de competências nas funções tecnológicas de Atividades de Processo e Organização da Produção e Atividades de Produto, na indústria denominada Alfa, no período de 1999 a 2008. Para consecução dos objetivos do trabalho será utilizado como ferramenta metodológica o estudo de caso. Na coleta das informações foram utilizadas as entrevistas, reuniões formais e consulta a documentos da indústria. Os modelos utilizados tratam das competências $e$ aprendizagem tecnológicas do autor Figueiredo (2001). Esses permitem mensurar niveis de capacitação tecnológica e identificar os quatro processos de aprendizagem e suas característicaschave.
\end{abstract}

Palavras-chave: Aprendizagem, Conhecimento e Competências.

\section{Introdução}

O atual ambiente de negócio e gestão é marcado pela intensidade e rapidez com que acontecem as mudanças nos cenários sóciopolítico, econômico e tecnológico.

Essas mudanças caracterizam o principal desafio a ser superado pelas organizações, sendo de fundamental importância mecanismos mais adequados para definir e redefinir suas competências e as formas de aprendizado.

Diante desse novo ambiente, é possível compreender uma maior valorização das pessoas nas organizações. Esse motivo acontece principalmente devido a necessidade dessas de apresentarem e receberem respostas mais rápidas para questões mais complexas, sendo necessárias novas formas de 
trabalho e mudança de postura pelas pessoas.

Essa nova forma de organização possui um ponto fundamental e decisivo, a necessidade de atuação pelas pessoas através de suas competências (habilidades, conhecimento e experiência), e esses três elementos são adquiridos e aprimorados através dos processos de aprendizagem.

A expressão "aprendizagem organizacional” refere-se aos vários mecanismos pelos quais os indivíduos adquirem habilidades e conhecimentos, e que possibilitam a conversão da aprendizagem individual para a aprendizagem organizacional (BELL, 1984).

Já "Competências", mais especificamente as competências tecnológicas, são aqui identificadas como os recursos necessários para gerar e gerenciar aperfeiçoamentos em atividades de processos e organização da produção, produtos, e desenvolvimento de novos produtos, processos produtivos e tecnologias. Tais recursos se acumulam e incorporam em indivíduos e sistemas organizacionais (BELL E PAVITT, 1995).

Segundo Figueiredo (2001) ao longo dos anos de 1990, um novo conjunto de estudos emergiu para examinar as implicações dos processos de aprendizagem na trajetória de acumulação de competência em indústrias de países em desenvolvimento.

No Brasil, vários estudos têm sido realizados vinculando os dois temas, dentre esses é possível destacar os trabalhos de:

Tacla (2002) estudou a trajetória de acumulação de competências tecnológicas e o relacionamento entre a acumulação de competências e os processos subjacentes de aprendizagem na indústria Kvaerner Pulping (indústria produtora de bens de capital sob encomenda para a indústria de celulose), em Curitiba - PR no período compreendido entre 1980 e 2000.

Martins (2005) analisou uma amostra de dezoito institutos brasileiros de pesquisa e desenvolvimento e também examinou as estratégias intra-organizacionais de aprendizagem e as interações dos institutos de pesquisa com a infra-estrutura tecnológica e com indústrias como fonte de conhecimento geradora de capacidades tecnológicas.

Miranda (2005) examinou a direção e velocidade de acumulação de capacidades tecnológicas na indústria de softwares no Brasil, além das principais fontes de capacidades tecnológicas para a manutenção dos tipos e níveis de capacidades correntes, as estratégias intraorganizacionais de aprendizagem e ligações estabelecidas pelas indústrias com a infra-estrutura tecnológica e outras indústrias.

Através da observação desses trabalhos, verificou-se a necessidade de se estudar como os processos de aprendizagem organizacional influenciam na acumulação de competências tecnológicas.

Diante do contexto inicial, o objetivo do trabalho é analisar como a aprendizagem organizacional influenciou na acumulação de competências nas funções tecnológicas de Atividades 
de Processo e Organização da Produção e Atividades de Produto, na indústria Alfa, no período de 1999 a 2008.

Além deste capítulo inicial que contextualiza o problema de pesquisa, são abordados no referencial teórico os principais conceitos de competência tecnológica, aprendizagem organizacional e os modelos de Figueiredo (2001). No tópico três são explicitados os procedimentos metodológicos para coleta e análise dos dados. Em seguida, são apresentados os resultados da pesquisa, e por fim, são feitas as considerações finais, mencionando a necessidade da realização de outros estudos para confirmar a base conceitual e conhecer como em outros contextos organizacionais são aplicados os mecanismos de aprendizagem organizacional e competência tecnológica.

\section{Competência - Principais Conceitos}

No domínio do senso comum a palavra competência é utilizada para designar uma pessoa qualificada para realizar alguma coisa. Já a palavra incompetência (antônimo) trás não só a negativa dessa qualificação, mas também sentimentos depreciativos e pejorativos.

$\mathrm{Na}$ idade média, essa expressão foi utilizada unicamente na linguagem jurídica e se referia à faculdade atribuída a alguém ou a alguma instituição para analisar e julgar certos assuntos.

Os juristas declaravam que determinada corte ou indivíduo era competente para um dado julgamento ou para realizar certo ato. Por extensão, o termo veio a designar o reconhecimento social sobre a capacidade de alguém pronunciar-se a respeito de determinado assunto. Mais tarde, o conceito de competência passou a ser utilizado de forma mais genérica, para qualificar o indivíduo capaz de realizar determinado trabalho (BRANDÃO E GUIMARÃES, 2001:2).

No contexto organizacional, com a publicação do paper Testing for competence rather than intelligence em 1973, McClelland iniciou o debate sobre competência entre os psicólogos e os dministradores nos Estados Unidos.

Diante desse conceito inicial de McClelland, surgiram vários novos conceitos e abordagens. Bitencourt (2001:28) em sua tese: “A gestão de competências gerenciais - a contribuição da aprendizagem organizacional" resgata os diversos conceitos ligados à questão das competências e as suas ênfases. O quadro 1 apresenta alguns desses autores.

Quadro 1: competência - principais autores, ênfases e conceitos

\begin{tabular}{|c|c|c|}
\hline Autor/ano & Ênfase & Conceito \\
\hline Boyatizis - 1982 & $\begin{array}{c}\text { Formação, comportamentos, } \\
\text { resultados }\end{array}$ & $\begin{array}{l}\text { As Competências são aspectos } \\
\text { verdadeiros ligados à natureza } \\
\text { humana. São comportamentos } \\
\text { observáveis que determinam, em } \\
\text { grande parte, o retorno da }\end{array}$ \\
\hline
\end{tabular}




\begin{tabular}{|c|c|c|}
\hline & & organização. \\
\hline Boterf (1997) & Mobilização e ação & $\begin{array}{l}\text { Competência é assumir } \\
\text { responsabilidades frente a } \\
\text { situações de trabalho complexas } \\
\text { buscando lidar com eventos } \\
\text { inéditos, surpreendentes, de } \\
\text { natureza singular. }\end{array}$ \\
\hline Fleury e Fleury (2000 & Ação e resultado & $\begin{array}{l}\text { Competência: um saber agir } \\
\text { responsável e reconhecido, que } \\
\text { implica mobilizar, integrar, } \\
\text { transferir conhecimentos, } \\
\text { recursos, habilidades, que } \\
\text { agreguem valor econômico à } \\
\text { organização e valor social ao } \\
\text { indivíduo. }\end{array}$ \\
\hline Bell e Pavitt (1995) & Aptidão, ação, resultado & 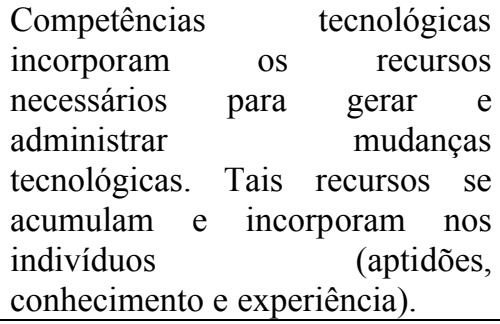 \\
\hline Figueiredo (2001) & Aptidão, ação, resultado & \begin{tabular}{llr} 
Competências & \multicolumn{2}{c}{ tecnológicas } \\
referem-se às & habilidades das \\
organizações & de realizarem \\
internamente & melhorias no \\
processo e na & organização da \\
produção, produtos, equipamentos \\
e projetos de engenharia.
\end{tabular} \\
\hline
\end{tabular}

Fonte: Adaptado de Bitencourt (2001)

A partir da leitura e discussão dos autores e abordagens, será utilizado e apresentado o postulado de Figueiredo (2001), este foi escolhido pela amplitude com que trata o tema Competências Tecnológicas.

\subsection{Acumulação de Competências Tecnológicas na Indústria Alfa}

O quadro 2 apresenta o modelo aplicado e adaptado de acumulação de competência do autor Figueiredo (2001) na indústria Alfa.

Quadro 2: Modelo de Acumulação de Competências Tecnológicas na Indústria Alfa

\begin{tabular}{|c|c|c|}
\hline \multirow{2}{*}{$\begin{array}{c}\text { Níveis de } \\
\text { Competência }\end{array}$} & \multicolumn{2}{|c|}{ Funções Tecnológicas e Atividades Afins } \\
\hline & Processo e Organização da Produção & Produto \\
\hline \multicolumn{3}{|c|}{ Competências de Rotina } \\
\hline $\begin{array}{c}(1) \\
\text { Básico }\end{array}$ & $\begin{array}{l}\text { - Atividades operacionais básicas; } \\
\text { - Gestão dos estoques de forma manual; } \\
\text { - Conferência dos embarques. }\end{array}$ & $\begin{array}{l}\text { - Análise aleatória da qualidade dos } \\
\text { produtos; } \\
\text { - Verificação das condições físicas dos } \\
\text { equipamentos de transporte para } \\
\text { distribuição física dos produtos. }\end{array}$ \\
\hline$(2)$ & - Implementação de códigos de barra; & - Análise automatizada da qualidade dos \\
\hline
\end{tabular}




\begin{tabular}{|c|c|c|}
\hline Renovado & $\begin{array}{l}\text { - Certificação dos processos de } \\
\text { qualidade e informatização dos } \\
\text { procedimentos técnicos. }\end{array}$ & $\begin{array}{l}\text { produtos; } \\
\text { - Certificação ISSO 9002; } \\
\text { - Certificação de FSC (Forest } \\
\text { Stewardship Council). }\end{array}$ \\
\hline \multicolumn{3}{|c|}{ Competências Inovadoras } \\
\hline $\begin{array}{c}(3) \\
\text { Extra-básico }\end{array}$ & $\begin{array}{l}\text { - Seleção padronizada da matéria-prima } \\
\text { por tamanho (diâmetro do tronco). }\end{array}$ & $\begin{array}{l}\text { - Desenvolvimento automatizado de } \\
\text { uma proteção para a superfície dos } \\
\text { produtos (MDF - Fibra de Média } \\
\text { Densidade). }\end{array}$ \\
\hline $\begin{array}{c}\text { (4) } \\
\text { Intermediário }\end{array}$ & $\begin{array}{l}\text { - Centralização dos processos de } \\
\text { programação de matéria-prima de forma } \\
\text { eletrônica (SAP); }\end{array}$ & $\begin{array}{l}\text { - Ampliação da aplicabilidade de um } \\
\text { produto existente através da adequação } \\
\text { de sua estrutura, permitindo uso em } \\
\text { diferentes locais. (MDF específico } \\
\text { desenvolvido para superfícies de mesa } \\
\text { foi adaptado para fabricação de um } \\
\text { novo tipo de porta). }\end{array}$ \\
\hline $\begin{array}{l}\text { (5) } \\
\text { Intermediário } \\
\text { superior }\end{array}$ & $\begin{array}{l}\text { - Controle informatizado para } \mathrm{o} \\
\text { lançamento de novos produtos } \mathrm{e} \\
\text { eliminação dos existentes. }\end{array}$ & $\begin{array}{l}\text { - Medição dos indicadores de qualidade } \\
\text { (possiveis ondulações do MDF) em } \\
\text { diferente locais do produto. }\end{array}$ \\
\hline $\begin{array}{c}(6) \\
\text { Avançado }\end{array}$ & $\begin{array}{l}\text { - Criação de mapas de gerenciamento } \\
\text { de lançamentos de novos produtos } \\
\text { através do Pesquisa e Desenvolvimento } \\
\text { (P\&D). }\end{array}$ & $\begin{array}{l}\text { - Desenvolvimento de novos padrões de } \\
\text { produtos com base na imagem perfeita } \\
\text { das madeiras brasileiras. (Premiação } \\
\text { nacional e internacional pelo } \\
\text { desenvolvimento de novos padrões de } \\
\text { produtos que respeitam o meio } \\
\text { ambiente). }\end{array}$ \\
\hline
\end{tabular}

Fonte: Pesquisa de campo

Segundo Figueiredo (2001), os níveis 1 (Básico) e 2 (Renovado) correspondem às competências de rotinas. Essas dizem a respeito a atividades tecnológicas realizadas num determinado nível de eficiência e utilização de insumos; são as aptidões necessárias para usar a tecnologia, os conhecimentos e os mecanismos organizacionais.

Já os níveis 3, 4, 5, e 6 referem às competências inovadoras. Essas permitem criar, modificar ou aperfeiçoar produtos e processos; são as aptidões necessárias para modificar tecnologias, os conhecimentos, a experiência e os mecanismos organizacionais (FIGUEIREDO, 2001).

O modelo permite mensurar o desenvolvimento de competências tecnológicas, com base em atividades que as indústrias são capazes de fazer, a partir de seu progresso de competências de rotina para níveis de competências inovadoras.

\subsection{Aprendizagem Organizacional - Principais Conceitos}

Aprendizagem inicialmente pode ser compreendida como um processo psicológico (processo neural complexo) que se inicia no indivíduo e leva a construção da memória. Esse conjunto de informações (memória) constitui a identidade do indivíduo. 
Para cada espécie animal a percepção do aprender é diferente. Nos seres humanos a percepção que prevalecer é a verbal e visual. A capacidade de aprendizagem através da percepção visual é superior que da percepção verbal, essas também são influenciadas por fatores como emoções e o afeto (FLEURY E FLEURY, 2006).

A partir desse pressuposto, o conceito de aprendizagem utilizado para esse trabalho refere-se a um grande processo de crescimento (influenciado pelas emoções e afetos) e de intercâmbio com o meio onde esse processo gera uma mudança de atitude no indivíduo.

Abbad (1999) fortifica o conceito definindo aprendizagem como o processo de mudança de comportamento do indivíduo não resultante apenas da sua maturação, mas também da interação com o meio.

Swieringa e Wierdsma (1995) afirmam que a mudança de atitude é resultado da aprendizagem. Logo, se houve mudança de atitude frente ao trabalho e à organização, pode-se afirmar que houve aprendizagem individual.

Tendo conhecimento da formação da aprendizagem no indivíduo é possível entender como acontece à aquisição na organização. Segundo Swieringa e Wierdsma (1995) o processo de aprendizagem organizacional pode ser caracterizado como natural e induzida.

A natural (forma mais primitiva de aprendizagem) ocorre de maneira informal sendo usada como principais técnicas à observação, imitação e repetidas tentativas.

Já a induzida, mais conhecida nos dia de hoje como treinamento, necessita de uma estrutura formalizada para induzir as pessoas a adquirir, acumular e transferir informações e conhecimentos. Além das diferenças na forma de aquisição de aprendizagem nas organizações, o conceito de aprendizagem é visto também por diferentes ângulos pelos administradores, como para os economistas e psicólogos.

Para os administradores a aprendizagem organizacional (está relacionado com a estratégia inovadora e eficiente) é o alicerce para a busca da vantagem competitiva sustentável. Os economistas tratam a aprendizagem (relacionando com a quantificação de resultados) como abstrações que podem proporcionar resultados quantificáveis (positivos).

E para os psicólogos a aprendizagem (relaciona com a eficiência organizacional) refere-se ao processo de construção e arranjo do conhecimento e das rotinas na organização ( DODGSON, 1993).

Segundo o mesmo autor, os psicólogos alertam para a diferenciação dos processos de aprendizagem, um ocorre no interior da pessoa que aprende e o outro das respostas, que podem ser mensuráveis, enviadas por esta pessoa.

Além dos diferentes pontos de vista de administradores, economistas e psicólogos sobre o tema, o quadro três a seguir procura resgatar os principais conceitos de aprendizagem 
organizacional e suas ênfases.

Lembrando que conceito de aprendizagem organizacional surgiu nos estudos desenvolvidos por Argyris e Schön em 1977. Os autores definiram a aprendizagem organizacional como um processo de identificação e correção de erros. A partir desse conceito, vários estudiosos ajudaram a fortificá-lo.

Quadro 3: Conceitos e Ênfases da Aprendizagem Organizacional

\begin{tabular}{|c|c|c|}
\hline Autor & Ênfase & Conceito \\
\hline Peter Senge (1990) & $\begin{array}{l}\text { Metanóia - mudança de } \\
\text { mentalidade, cinco } \\
\text { disciplinas. }\end{array}$ & $\begin{array}{l}\text { A aprendizagem acontece através das } \\
\text { interações continuadas com o meio. } \\
\text { As pessoas elevam a capacidade de } \\
\text { criar resultados, diante disso brotam } \\
\text { padrões elevados de raciocínio e } \\
\text { condições de aprendizagem em } \\
\text { grupo. }\end{array}$ \\
\hline $\begin{array}{c}\text { Nonaka e Takeuchi } \\
\text { (1997) }\end{array}$ & $\begin{array}{c}\text { Apropriação e } \\
\text { disseminação do } \\
\text { conhecimento; } \\
\text { conhecimento explícito e } \\
\text { tácito. }\end{array}$ & $\begin{array}{l}\text { A aprendizagem organizacional é } \\
\text { intimamente relacionada ao aprender } \\
\text { fazendo. Quando são internalizados } \\
\text { nas bases do conhecimento tácito dos } \\
\text { indivíduos sob a forma de modelos } \\
\text { mentais ou know-how técnico } \\
\text { compartilhado, as experiências } \\
\text { através da socialização, } \\
\text { externalização e combinação tornam- } \\
\text { se ativos valiosos. }\end{array}$ \\
\hline $\begin{array}{l}\text { Probst e Büchel } \\
\text { (1994) }\end{array}$ & $\begin{array}{l}\text { Conhecimentos, valores, } \\
\text { mudança. }\end{array}$ & $\begin{array}{l}\text { Aprendizagem organizacional trata } \\
\text { de habilidades das organizações para } \\
\text { detectar, corrigir e aprender através } \\
\text { dos erros sempre melhorando a base } \\
\text { do seu conhecimento. }\end{array}$ \\
\hline Figueiredo (2003) & $\begin{array}{l}\text { Acumulação de } \\
\text { competências } \\
\text { tecnológicas através da } \\
\text { aprendizagem }\end{array}$ & $\begin{array}{l}\text { Aprendizagem dividida em dois } \\
\text { processos distintos: a) } \mathrm{O} \text { processo de } \\
\text { aquisição de conhecimento (plano } \\
\text { individual); e b) O processo de } \\
\text { conversão de conhecimento (plano } \\
\text { organizacional). }\end{array}$ \\
\hline
\end{tabular}

Fonte: Adaptado de Bitencourt (2001)

Seguindo o objetivo da pesquisa, o modelo escolhido para analisar os processos de aprendizagem também trata do modelo de Figueiredo (2001). 


\subsection{Processos de Aprendizagem}

O quadro 4 apresenta o modelo de acumulação de competência do autor Figueiredo (2001) na indústria Alfa.

Quadro 4: Principais características dos processos de aprendizagem na indústria de país emergente: modelo ilustrativo

\begin{tabular}{|c|c|c|c|}
\hline \multirow[b]{2}{*}{$\begin{array}{c}\text { Processos de } \\
\text { Aprendizagem }\end{array}$} & \multicolumn{3}{|c|}{ Características-chave dos processos de aprendizagem } \\
\hline & $\begin{array}{c}\text { Variedade } \\
\text { Ausente, Inexistente, } \\
\text { Limitada, Moderada, } \\
\text { Diversa. } \\
\end{array}$ & $\begin{array}{c}\text { Intensidade } \\
\text { Uma vez, Intermitente, } \\
\text { Contínua. }\end{array}$ & $\begin{array}{c}\text { Funcionamento } \\
\text { Insatisfatório, Moderado, } \\
\text { Bom, Excelente. }\end{array}$ \\
\hline \multicolumn{4}{|c|}{ Processos de Aquisição de Conhecimento } \\
\hline $\begin{array}{l}\text { Aquisição Externa de } \\
\text { Conhecimento }\end{array}$ & $\begin{array}{c}\text { Presença/ausência de } \\
\text { processos para adquirir } \\
\text { conhecimento } \\
\text { localmente ou no } \\
\text { exterior (ex. } \\
\text { treinamento, } \\
\text { fornecedores, usuários, } \\
\text { contratação de expertise, } \\
\text { laboratórios, } \\
\text { universidades, } \\
\text { assistência técnica). }\end{array}$ & $\begin{array}{l}\text { Modo como à indústria } \\
\text { usa este processo ao } \\
\text { longo do tempo, pode ser } \\
\text { contínuo, intermitente, } \\
\text { ou uma só vez. }\end{array}$ & $\begin{array}{l}\text { Modo como o processo } \\
\text { foi criado e como ele } \\
\text { opera ao longo do } \\
\text { tempo. }\end{array}$ \\
\hline $\begin{array}{l}\text { Aquisição Interna de } \\
\text { Conhecimento }\end{array}$ & $\begin{array}{l}\text { Presença/ausência de } \\
\text { processos para adquirir } \\
\text { conhecimento em } \\
\text { atividades internas de } \\
\text { rotina ou inovadoras: } \\
\text { experimentação } \\
\text { sistemática, } \\
\text { treinamentos. }\end{array}$ & $\begin{array}{c}\text { Modo como a indústria } \\
\text { usa diferentes processos } \\
\text { para aquisição interna de } \\
\text { conhecimento. }\end{array}$ & $\begin{array}{l}\text { Modo como o processo } \\
\text { foi criado e opera ao } \\
\text { longo do tempo; tem } \\
\text { implicações para } \\
\text { variedade e intensidade. }\end{array}$ \\
\hline \multicolumn{4}{|c|}{ Processos de Conversão de Conhecimento } \\
\hline $\begin{array}{l}\text { Compartilhamento } \\
\text { (socialização) de } \\
\text { Conhecimento }\end{array}$ & $\begin{array}{c}\text { Presença/ausência de } \\
\text { diferentes processos } \\
\text { através dos quais } \\
\text { indivíduos compartilham } \\
\text { seu conhecimento tácito } \\
\text { (ex. solução } \\
\text { compartilhada de } \\
\text { problemas, times, } \\
\text { rotação no trabalho, } \\
\text { treinamentos diversos, } \\
\text { prototipagem). }\end{array}$ & $\begin{array}{l}\text { Modo como processos } \\
\text { prosseguem ao longo dos } \\
\text { anos. Intensidade } \\
\text { contínua do processo de } \\
\text { compartilhamento pode } \\
\text { influenciar codificação } \\
\text { de conhecimento. }\end{array}$ & $\begin{array}{c}\text { Modo como mecanismos } \\
\text { de compartilhamento são } \\
\text { criados e operam ao } \\
\text { longo do tempo. Tem } \\
\text { implicações p/ a } \\
\text { variedade e intensidade } \\
\text { do processo de } \\
\text { conversão. }\end{array}$ \\
\hline $\begin{array}{l}\text { Codificação de } \\
\text { Conhecimento }\end{array}$ & $\begin{array}{l}\text { Presença/ausência de } \\
\text { diferentes processos para } \\
\text { formatar o conhecimento } \\
\text { tácito (ex. manuais, } \\
\text { formatos organizados, } \\
\text { software, padrões, } \\
\text { projetos, } \\
\text { procedimentos). }\end{array}$ & $\begin{array}{l}\text { Modo como processos } \\
\text { de padronização de } \\
\text { operações são } \\
\text { repetidamente feitos. } \\
\text { Codificação ausente ou } \\
\text { intermitente pode limitar } \\
\text { a aprendizagem } \\
\text { organizacional. }\end{array}$ & $\begin{array}{c}\text { Modo como a } \\
\text { codificação do } \\
\text { conhecimento foi criada } \\
\text { e opera ao longo do } \\
\text { tempo. Tem implicações } \\
\text { para o funcionamento de } \\
\text { todo o processo de } \\
\text { conversão. }\end{array}$ \\
\hline
\end{tabular}

Fonte: Figueiredo (2001) 
Segundo Figueiredo (2001) o modelo é dividido em quatro fases: Aquisição Externa de Conhecimento; Aquisição Interna de Conhecimento; Compartilhamento (socialização) de Conhecimento; Codificação de Conhecimento.

- Aquisição externa: mecanismos de aquisição de conhecimento tácito e/ou codificado de fora da indústria.

- Aquisição interna: mecanismos para aquisição de conhecimento tácito por meio de diferentes atividades realizadas dentro da indústria.

- Compartilhamento (socialização) e codificação: convertem conhecimento individual em organizacional. Os mecanismos de compartilhamento permitem que alguma parte do conhecimento tácito seja transmitida.

Apresentado os principais conceitos de competência tecnológica e aprendizagem organizacional, além dos modelos de Figueiredo (2001), o próximo capítulo aborda os procedimentos metodológicos.

\section{Procedimentos Metodológicos}

O presente estudo tem como objetivo analisar como os processos de aprendizagem influenciaram na acumulação de competências nas funções tecnológicas Atividades de Processo e Organização da Produção e Atividades de Produto na indústria Alfa.

Portanto para a consecução dos objetivos do trabalho foi utilizado como ferramenta metodológica o estudo de caso (Yin, 1994). Já para a coleta das informações foram utilizadas fontes múltiplas:

- As entrevistas;

- Reuniões formais com o gerente de Recursos Humanos;

- Consulta a documentos da indústria;

Após a coleta das informações, foi realizada à análise das estruturas analíticas dos vários mecanismos de aprendizagem, considerando cada uma das características. Essas com base em três critérios:

Variedade - critério de avaliação - (Presença ou Ausência) de Mecanismos de aquisição, compartilhamento e codificação de conhecimento.

Intensidade - critério de avaliação - (Uma vez - Intermitente - Contínuo) de Mecanismos de aquisição, compartilhamento e codificação de conhecimento.

Funcionamento - critério de avaliação - (Insatisfatório - Moderado - Bom - Excelente) de Mecanismos de aquisição, compartilhamento e codificação de conhecimento. 


\section{Acumulação de Competências Tecnológicas em Atividades de Processo e Organização da Produção e de Produto na Indústria Alfa (1999 a 2008)}

Para melhor entendimento a figura 1 apresenta como aconteceu à acumulação das competências tecnológicas na indústria em estudo.

Figura 1: Acumulação das Competências Tecnológicas na Indústria Alfa

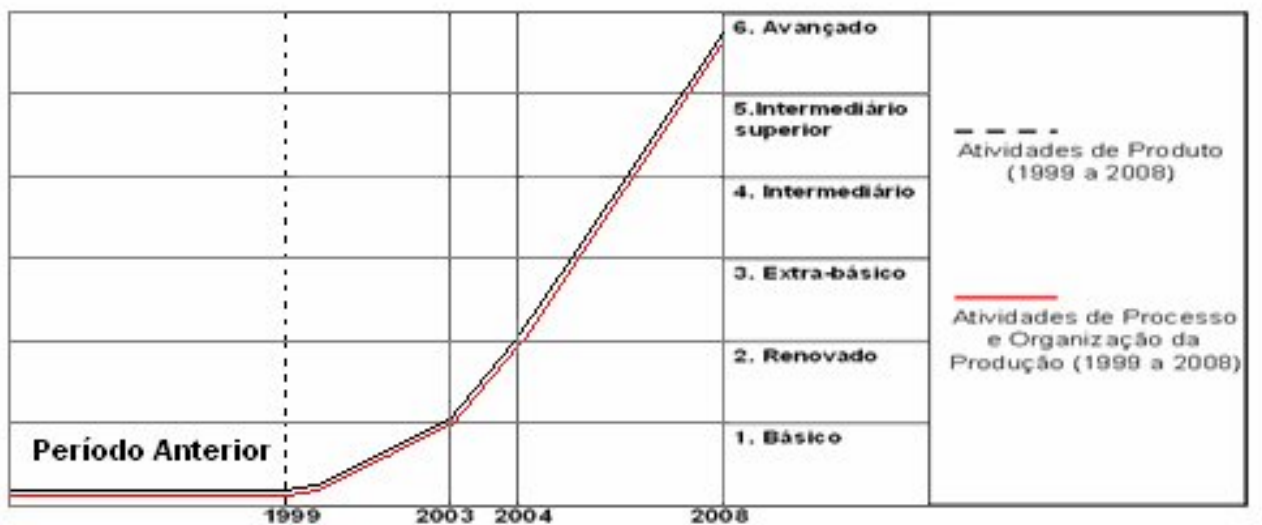

Fonte: Pesquisa de Campo

Em 1999 a indústria Alfa utilizava para acumular competências às tecnologias já existentes. Essas tecnologias eram suficientes para competir com os concorrentes regionais e nacionais. Também nesse período a indústria começa a desenvolver uma cultura voltada para as competências inovadoras, conforme explicitado no quadro 2. Diante da analise inicial e de acordo com o modelo as competências se enquadram no Nível Básico (1).

Com a implementação do uso de novas tecnologias, (informatização de grande parte do seu processo produtivo), passa a utilizar código de barra, análise automatizada da qualidade dos seus produtos e consegue certificação ISO 9002 e FSC (Forest Stewardship Council), a indústria Alfa aumentou suas competência para o Nível Renovado (2).

Após esse período a indústria avança, e passa a desenvolver tecnologia própria para com seus processos e organização da produção como também para seus produtos. Usa matériaprima já padronizada (cada produto utiliza um tipo de tronco com o mesmo diâmetro) e desenvolve um novo tipo de proteção com intuito de proteger a superfície dos seus produtos (principalmente no seu transporte). Nessa etapa fica consolidada a acumulação de competência no Nível Extra-Básico (3).

Já no período de 2005 a 2006 a indústria Alfa diferencia novamente dos seus concorrentes com a compra da ferramenta de Tecnologia de Informação (SAP) para inovar na centralização dos processos de programação de matéria-prima. Em relação aos produtos, foi desenvolvida uma nova aplicabilidade para o uso de um tipo de matéria-prima que só tinha finalidade para a fabricação de 
tampo de mesa, sendo também aplicado agora para a fabricação de portas. Nesse período as competências da indústria Alfa alcançam o Nível Intermediário (4).

O Nível de competência denominado Intermediário Superior (5) foi alcançado graças a um novo tipo de controle informatizado que faz o lançamento de novos produtos e elimina os existentes. Em relação ao produto, desenvolve uma nova medição para manter a qualidade para verificar possíveis ondulações nas placas de MDF (Fibra de Média Densidade).

E para o maior Nível de competência, o Avançado (6) a indústria Alfa criou e utiliza os novos produtos desenvolvidos pelo setor de Pesquisa e Desenvolvimento (P\&D), existindo uma estrutura inovadora que faz todo esse mapeamento desde a idéia inicial até o produto final. Já em relação ao produto a indústria desenvolveu novos padrões de placas de MDF utilizando a imagem de madeiras nobres encontrada nas florestas brasileiras. Com esse tipo de tecnologia, foi possível imitar as ranhuras de madeiras como, por exemplo, o mogno e outras madeiras nobres para as placas de MDF. Com a utilização dessa tecnologia a indústria Alfa ganhou premiações nacionais e internacionais.

\subsection{Fatores que Influenciam na Acumulação de Competências: Os Processos de Aprendizagem}

\section{- Variedade dos Processos de Aprendizagem}

$\mathrm{O}$ primeiro critério analisado dos processos de aprendizagem organizacional refere-se à Variedade. A tabela 1 resume como a indústria Alfa adquire, compartilha e codifica o conhecimento.

Tabela 1: Resumo da Variedade dos Processos de Aprendizagem

\begin{tabular}{|c|c|c|}
\hline \multirow[t]{2}{*}{ Processos e Mecanismos de Aquisição Externa de Conhecimento } & \multicolumn{2}{|c|}{$\begin{array}{l}\text { Presença ou Ausência de } \\
\text { Mecanismos }\end{array}$} \\
\hline & 1999 a 2003 & 2004 a 2008 \\
\hline 1. Convênios com escolas e institutos. & Presente & Presente \\
\hline 2. Aquisição de indústria líder da indústria. & - & Presente \\
\hline 3. Visitas técnicas para aquisição de máquinas de tecnologia & Presente & Presente \\
\hline 4. Aprendizado via contrato de licenciamento & Presente & Presente \\
\hline 5. Joint-venture com indústria estrangeira & - & - \\
\hline $\begin{array}{l}\text { 6. Contrato de transferência tecnológica com indústria expertise da } \\
\text { indústria }\end{array}$ & - & - \\
\hline 7. Participação em feiras e eventos relacionados à indústria & Presente & Presente \\
\hline 8. Acesso a conhecimento externo codificado & Presente & Presente \\
\hline 9. Contratação de engenheiros experientes & Presente & Presente \\
\hline $\begin{array}{l}\text { 10. Interação com usuários e clientes para aprimoramento de produtos e } \\
\text { processos }\end{array}$ & Presente & Presente \\
\hline $\begin{array}{l}\text { 11. Participação de usuários e grandes clientes na conceituação de } \\
\text { produtos (focus group) }\end{array}$ & - & Presente \\
\hline Processos e mecanismos de aquisição interna de conhecimento & rresen & êneia de \\
\hline
\end{tabular}




\begin{tabular}{|c|c|c|}
\hline & \multicolumn{2}{|c|}{ Mecanismos } \\
\hline & 1999 a 2003 & 2004 a 2008 \\
\hline 1. Envolvimento em projeto da planta 2 (filial) & - & Presente \\
\hline 2. Instalação e operação da planta 2 & - & Presente \\
\hline 3. Melhoria em linhas de produção & Presente & Presente \\
\hline 4. Aquisição de conhecimento antes de engajar em novas atividades & Presente & Presente \\
\hline $\begin{array}{l}\text { 5. Experimentação em laboratório e linha de produção para } \\
\text { desenvolvimento de produtos e processos }\end{array}$ & Presente & Presente \\
\hline 6. Estudos em laboratórios e manipulação de parâmetros de produção & Presente & Presente \\
\hline $\begin{array}{l}\text { 7. Esforços sistemáticos em aprimoramento contínuo em processos e } \\
\text { produtos }\end{array}$ & Presente & Presente \\
\hline 8. Prototipagem para desenvolvimento de novos produtos & Presente & Presente \\
\hline \multirow{2}{*}{$\begin{array}{c}\text { Processos e mecanismos de compartilhamento (socialização) de } \\
\text { conhecimento }\end{array}$} & \multicolumn{2}{|c|}{$\begin{array}{l}\text { Presença ou Ausência de } \\
\text { Mecanismos }\end{array}$} \\
\hline & 1999 a 2003 & 2004 a 2008 \\
\hline 1. Formação básica e fundamental para operários da linha de produção & Presente & Presente \\
\hline 2. Treinamentos internos realizados por especialistas da indústria & Presente & Presente \\
\hline 3. Treinamento on the job (OJT) & Presente & Presente \\
\hline 4. Treinamento por observação & Presente & Presente \\
\hline 5. Solução compartilhada de problemas (brainstorming, simulações) & Presente & Presente \\
\hline 6. Benchmarking para desenvolvimento de produtos e processos & Presente & Presente \\
\hline 7. Links de comunicação entre indústrias do grupo & Presente & Presente \\
\hline 8. Software para compartilhar conhecimento em projetos de design & Presente & Presente \\
\hline $\begin{array}{l}\text { 9. Links para compartilhar conhecimento tácito e codificado entre } \\
\text { especialistas da indústria }\end{array}$ & Presente & Presente \\
\hline $\begin{array}{l}\text { 10. Comunicação para disseminar novos processos de produção e } \\
\text { ocorrência de eventos internos. (ex: implantação de Kaizen). }\end{array}$ & Presente & Presente \\
\hline 11. Construção formal de grupos de projeto. & - & Presente \\
\hline \multirow[t]{2}{*}{ Processos e mecanismos de codificação de conhecimento } & \multicolumn{2}{|c|}{$\begin{array}{l}\text { Presença ou Ausência de } \\
\text { Mecanismos }\end{array}$} \\
\hline & 1999 a 2003 & 2004 a 2008 \\
\hline 1. Manuais para a padronização de práticas de produção. & - & Presente \\
\hline 2. Codificação de projetos. & - & Presente \\
\hline 3. Comunicação interna impressa. & - & Presente \\
\hline $\begin{array}{l}\text { 4. Codificação de conhecimento interno, próprio da indústria (ex. via } \\
\text { intranet). }\end{array}$ & Presente & Presente \\
\hline $\begin{array}{l}\text { 5. Relatórios da divisão de serviços ao cliente para gerar melhorias em } \\
\text { produtos e assistência técnica. }\end{array}$ & Presente & Presente \\
\hline 6. Sistema visuais de aprendizagem. & - & Presente \\
\hline
\end{tabular}

Fonte: Pesquisa de campo

A partir dos dados é possível inferir que a indústria no período de 1999 a 2003 não utilizou onze instrumentos de aprendizagem, o que pode ter levado a ela permanecer nesse período com suas competências no nível básico (1).

Já a partir de 2004 a mesma agrega quase todos os instrumentos de aprendizagem pesquisados e consegue alcançar a uma variedade de conhecimentos.

\section{- Intensidade dos Processos de Aprendizagem}

O segundo critério analisado trata-se da Intensidade. A tabela 2 resume como a indústria Alfa adquire, compartilha e codificação o conhecimento. 
Tabela 2: Resumo da Intensidade dos Processos de Aprendizagem

\begin{tabular}{|c|c|c|}
\hline \multirow{2}{*}{$\begin{array}{l}\text { Processos e Mecanismos de Aquisição Externa de } \\
\text { Conhecimento }\end{array}$} & \multicolumn{2}{|c|}{ Uma vez- Intermitente - Contínuo } \\
\hline & 1999 a 2003 & 2004 a 2008 \\
\hline 1. Convênios com escolas e institutos. & Contínuo & Contínuo \\
\hline 2. Aquisição de indústria líder da indústria. & - & Contínuo \\
\hline 3. Visitas técnicas para aquisição de máquinas de tecnologia & Contínuo & Contínuo \\
\hline 4. Aprendizado via contrato de licenciamento & Contínuo & Contínuo \\
\hline 5. Joint-venture com indústria estrangeira & - & - \\
\hline $\begin{array}{l}\text { 6. Contrato de transferência tecnológica com indústria expertise da } \\
\text { indústria }\end{array}$ & - & - \\
\hline 7. Participação em feiras e eventos relacionados à indústria & Contínuo & Contínuo \\
\hline 8. Acesso a conhecimento externo codificado & Contínuo & Contínuo \\
\hline 9. Contratação de engenheiros experientes & Contínuo & Contínuo \\
\hline $\begin{array}{l}\text { 10. Interação com usuários e clientes para aprimoramento de } \\
\text { produtos e processos }\end{array}$ & Contínuo & Contínuo \\
\hline $\begin{array}{l}\text { 11. Participação de usuários e grandes clientes na conceituação de } \\
\text { produtos (focus group) }\end{array}$ & Uma vez & Contínuo \\
\hline \multirow{2}{*}{ Processos e mecanismos de aquisição interna de conhecimento } & \multicolumn{2}{|c|}{ Uma vez- Intermitente - Contínuo } \\
\hline & 1999 a 2003 & 2004 a 2008 \\
\hline 1. Envolvimento em projeto da planta 2 (filial) & - & Contínuo \\
\hline 2. Instalação e operação da planta 2 & - & Contínuo \\
\hline 3. Melhoria em linhas de produção & Contínuo & Contínuo \\
\hline $\begin{array}{l}\text { 4. Aquisição de conhecimento antes de engajar em novas } \\
\text { atividades }\end{array}$ & Contínuo & Contínuo \\
\hline $\begin{array}{l}\text { 5. Experimentação em laboratório e linha de produção para } \\
\text { desenvolvimento de produtos e processos }\end{array}$ & Contínuo & Contínuo \\
\hline $\begin{array}{l}\text { 6. Estudos em laboratórios e manipulação de parâmetros de } \\
\text { produção }\end{array}$ & Contínuo & Contínuo \\
\hline $\begin{array}{l}\text { 7. Esforços sistemáticos em aprimoramento contínuo em processos } \\
\text { e produtos }\end{array}$ & Contínuo & Contínuo \\
\hline 8. Prototipagem para desenvolvimento de novos produtos & Contínuo & Contínuo \\
\hline \multirow{2}{*}{$\begin{array}{l}\text { Processos e mecanismos de compartilhamento (socialização) de } \\
\text { conhecimento }\end{array}$} & \multicolumn{2}{|c|}{ Uma vez- Intermitente - Contínuo } \\
\hline & 1999 a 2003 & 2004 a 2008 \\
\hline $\begin{array}{l}\text { 1. Formação básica e fundamental para operários da linha de } \\
\text { produção }\end{array}$ & Contínuo & Contínuo \\
\hline 2. Treinamentos internos realizados por especialistas da indústria & Contínuo & Contínuo \\
\hline 3. Treinamento on the job (OJT) & Contínuo & Contínuo \\
\hline 4. Treinamento por observação & Contínuo & Contínuo \\
\hline $\begin{array}{l}\text { 5. Solução compartilhada de problemas (brainstorming, } \\
\text { simulações) }\end{array}$ & Contínuo & Contínuo \\
\hline 6. Benchmarking para desenvolvimento de produtos e processos & Contínuo & Contínuo \\
\hline 7. Links de comunicação entre indústrias do grupo & Contínuo & Contínuo \\
\hline 8. Software para compartilhar conhecimento em projetos de design & Contínuo & Contínuo \\
\hline $\begin{array}{l}\text { 9. Links para compartilhar conhecimento tácito e codificado entre } \\
\text { especialistas da indústria }\end{array}$ & Contínuo & Contínuo \\
\hline $\begin{array}{l}\text { 10. Comunicação para disseminar novos processos de produção e } \\
\text { ocorrência de eventos internos. (ex: implantação de Kaizen). }\end{array}$ & Contínuo & Contínuo \\
\hline 11. Construção formal de grupos de projeto. & - & Contínuo \\
\hline \multirow{2}{*}{ Processos e mecanismos de codificação de conhecimento } & \multicolumn{2}{|c|}{ Uma vez- Intermitente - Contínuo } \\
\hline & 1999 a 2003 & 2004 a 2008 \\
\hline 1. Manuais para a padronização de práticas de produção. & - & Contínuo \\
\hline 2. Codificação de projetos. & - & Contínuo \\
\hline 3. Comunicação interna impressa. & - & Contínuo \\
\hline $\begin{array}{l}\text { 4. Codificação de conhecimento interno, próprio da indústria (ex. } \\
\text { via intranet). }\end{array}$ & Contínuo & Contínuo \\
\hline $\begin{array}{l}\text { 5. Relatórios da divisão de serviços ao cliente para gerar melhorias } \\
\text { em produtos e assistência técnica. }\end{array}$ & Contínuo & Contínuo \\
\hline 6. Sistema visuais de aprendizagem. & - & Contínuo \\
\hline
\end{tabular}

Fonte: Pesquisa de campo 
Em relação aos quatro processos analisados é possível inferir que no período de 1999 a 2003 dez mecanismos de aprendizagem não foram utilizados pela indústria Alfa, sendo assim caracterizado pelo modelo aplicado como insatisfatório.

Já a partir de 2004, só dois instrumentos não foram utilizados (joint-venture com indústria estrangeira e contrato de transferência tecnológica com indústria expertise da indústria) o que possibilitou a indústria alcançar uma maior intensidade de conhecimentos.

\section{- Funcionamento dos Processos de Aprendizagem}

A tabela 3 resume como a indústria Alfa adquire, compartilha e codificação o conhecimento.

Tabela 3: Resumo do Funcionamento dos Processos de Aprendizagem

\begin{tabular}{|c|c|c|}
\hline \multirow{2}{*}{$\begin{array}{l}\text { Processos e Mecanismos de Aquisição Externa de } \\
\text { Conhecimento }\end{array}$} & \multicolumn{2}{|c|}{$\begin{array}{l}\text { Insatisfatório - Moderado - Bom - } \\
\text { Excelente }\end{array}$} \\
\hline & 1999 a 2003 & 2004 a 2008 \\
\hline 1. Convênios com escolas e institutos. & Excelente & Excelente \\
\hline 2. Aquisição de indústria líder da indústria. & - & Bom \\
\hline 3. Visitas técnicas para aquisição de máquinas de tecnologia & Excelente & Excelente \\
\hline 4. Aprendizado via contrato de licenciamento & Excelente & Excelente \\
\hline 5. Joint-venture com indústria estrangeira & - & - \\
\hline $\begin{array}{l}\text { 6. Contrato de transferência tecnológica com indústria } \\
\text { expertise da indústria }\end{array}$ & - & - \\
\hline 7. Participação em feiras e eventos relacionados à indústria & Excelente & Excelente \\
\hline 8. Acesso a conhecimento externo codificado & Excelente & Excelente \\
\hline 9. Contratação de engenheiros experientes & Excelente & Excelente \\
\hline $\begin{array}{l}\text { 10. Interação com usuários e clientes para aprimoramento de } \\
\text { produtos e processos }\end{array}$ & Excelente & Excelente \\
\hline $\begin{array}{l}\text { 11. Participação de usuários e grandes clientes na } \\
\text { conceituação de produtos (focus group) }\end{array}$ & Moderado & Bom \\
\hline \multirow{2}{*}{$\begin{array}{c}\text { Processos e mecanismos de aquisição interna de } \\
\text { conhecimento }\end{array}$} & \multicolumn{2}{|c|}{$\begin{array}{l}\text { Insatisfatório - Moderado - Bom - } \\
\text { Excelente }\end{array}$} \\
\hline & 1999 a 2003 & 2004 a 2008 \\
\hline 1. Envolvimento em projeto da planta 2 (filial) & - & Excelente \\
\hline 2. Instalação e operação da planta 2 & - & Moderado \\
\hline 3. Melhoria em linhas de produção & Excelente & Excelente \\
\hline $\begin{array}{l}\text { 4. Aquisição de conhecimento antes de engajar em novas } \\
\text { atividades }\end{array}$ & Excelente & Excelente \\
\hline $\begin{array}{l}\text { 5. Experimentação em laboratório e linha de produção para } \\
\text { desenvolvimento de produtos e processos }\end{array}$ & Excelente & Excelente \\
\hline $\begin{array}{l}\text { 6. Estudos em laboratórios e manipulação de parâmetros de } \\
\text { produção }\end{array}$ & Excelente & Excelente \\
\hline $\begin{array}{l}\text { 7. Esforços sistemáticos em aprimoramento contínuo em } \\
\text { processos e produtos }\end{array}$ & Excelente & Excelente \\
\hline 8. Prototipagem para desenvolvimento de novos produtos & Excelente & Excelente \\
\hline \multirow{2}{*}{$\begin{array}{l}\text { Processos e mecanismos de compartilhamento } \\
\text { (socialização) de conhecimento }\end{array}$} & \multicolumn{2}{|c|}{$\begin{array}{l}\text { Insatisfatório - Moderado - Bom - } \\
\text { Excelente }\end{array}$} \\
\hline & 1999 a 2003 & 2004 a 2008 \\
\hline $\begin{array}{l}\text { 1. Formação básica e fundamental para operários da linha de } \\
\text { produção }\end{array}$ & Excelente & Excelente \\
\hline $\begin{array}{l}\text { 2. Treinamentos internos realizados por especialistas da } \\
\text { indústria }\end{array}$ & Excelente & Excelente \\
\hline 3. Treinamento on the job (OJT) & Excelente & Excelente \\
\hline
\end{tabular}




\begin{tabular}{|c|c|c|}
\hline 4. Treinamento por observação & Excelente & Excelente \\
\hline $\begin{array}{l}\text { 5. Solução compartilhada de problemas (brainstorming, } \\
\text { simulações) }\end{array}$ & Excelente & Excelente \\
\hline $\begin{array}{l}\text { 6. Benchmarking para desenvolvimento de produtos e } \\
\text { processos }\end{array}$ & Excelente & Excelente \\
\hline 7. Links de comunicação entre indústrias do grupo & Excelente & Excelente \\
\hline $\begin{array}{l}\text { 8. Software para compartilhar conhecimento em projetos de } \\
\text { design }\end{array}$ & Excelente & Excelente \\
\hline $\begin{array}{l}\text { 9. Links para compartilhar conhecimento tácito e codificado } \\
\text { entre especialistas da indústria }\end{array}$ & Excelente & Excelente \\
\hline $\begin{array}{l}\text { 10. Comunicação para disseminar novos processos de } \\
\text { produção e ocorrência de eventos internos. (ex: implantação } \\
\text { de Kaizen). }\end{array}$ & Excelente & Excelente \\
\hline 11. Construção formal de grupos de projeto. & Moderado & Excelente \\
\hline \multirow[t]{2}{*}{ Processos e mecanismos de codificação de conhecimento } & \multicolumn{2}{|c|}{$\begin{array}{l}\text { Insatisfatório - Moderado - Bom - } \\
\text { Excelente } \\
\end{array}$} \\
\hline & 1999 a 2003 & 2004 a 2008 \\
\hline 1. Manuais para a padronização de práticas de produção. & - & Excelente \\
\hline 2. Codificação de projetos. & - & Excelente \\
\hline 3. Comunicação interna impressa. & - & Excelente \\
\hline $\begin{array}{l}\text { 4. Codificação de conhecimento interno, próprio da indústria } \\
\text { (ex. via intranet). }\end{array}$ & Excelente & Excelente \\
\hline $\begin{array}{l}\text { 5. Relatórios da divisão de serviços ao cliente para gerar } \\
\text { melhorias em produtos e assistência técnica. }\end{array}$ & Bom & Excelente \\
\hline 6. Sistema visuais de aprendizagem. & - & Excelente \\
\hline
\end{tabular}

Fonte: Pesquisa de campo

Em relação aos quatro processos analisados é possível inferir que alguns instrumentos de aprendizagem nos primeiros cinco anos não foram utilizados.

Já nos anos de 2004 a 2008 esses processos passam a apresentar níveis excelentes de funcionamento em relação à aquisição, compartilhamento e codificação de conhecimento.

\section{Considerações Finais}

O artigo examinou como a aprendizagem organizacional influenciou na acumulação de competências nas funções tecnológicas de Atividades de Processo e Organização da Produção e Atividades de Produto, na indústria Alfa, no período de 1999 a 2008.

Embora haja limitações típicas decorrentes de estudos de caso individual, este artigo colaborou para explicar como uma indústria localizada em um país em desenvolvimento pode acumular competências de rotinas e transforma-las inovadoras.

No período estudado, o modelo de processo de aprendizagem verificou a importância dos critérios variedade, intensidade e modo de funcionamento de certos mecanismos, que permitiram a criação de sólida base de conhecimento.

É possível inferir que quanto mais instrumentos de aprendizagem foram agregados, e utilizados de forma contínua e com bons níveis de funcionamento, melhor e mais rápido foi a acumulação de competência. 
Deve-se destacar que os conceitos apresentados são de relevante importância para se entender a verdadeira natureza da acumulação de competências tecnológicas da organização. No entanto, as teorizações e evidências apresentadas não têm a pretensão de ser uma teoria definitiva e sim visam estimular o debate e a crítica junto à comunidade acadêmica.

\begin{abstract}
The objective in this work is to analyze how the organizational learning influenced the accumulation of competences in the technological functions of Activities of Process and Production Organization and Activities of Products in the industry called Alfa from 1999 to 2008. To accomplish the objectives of this work a case study is used as a methodological tool. For the information collecting it was used interviews, meetings and consults to the industry documents. The used models consider the technological competences and learning of Figueiredo (2001). These models allow to measure the level of the technological capabilities and to identify the four learning process and their key characteristics.
\end{abstract}

Key-words: Learning, Knowledge, Competence

\title{
Agradecimentos
}

Os autores agradecem a Coordenação de Aperfeiçoamento de Pessoal de Nível Superior - CAPES pelo financiamento da pesquisa.

\section{Referências}

ABBAD, G. Um modelo integrado de avaliação do impacto do treinamento no trabalho - IMPACT. 1999. 262 f. Tese. (Doutorado em Psicologia). Instituto de Psicologia. Universidade de Brasília, Brasília. 1999.

Bell, M. Learning and the accumulation of industrial technological capacity in developing countries. In K. King \& M. Fransman (Eds.). Technological capability in the third world. London: Macmillan (1984).

Bell, M., \& Pavitt, K.. The development of technological capabilities. In I. U. Haque (Ed.). Trade, technology and international competitiveness. Washington: The World Bank (1995).

BITENCOURT, C. C. A gestão de competências gerenciais - a contribuição da aprendizagem organizacional. Tese (doutorado). Porto Alegre, 2001.

BRANDÃO, H. P.; GUIMARÃES, T. A. Gestão de competências e gestão de desempenho: tecnologias distintas ou instrumentos de um mesmo construto? Revista de administração de indústrias, RAI. v1.n1. jan-mar, 2001.

DODGSON, M. Organizational Learning: a review of some literatures. Organization Studies, 1993.

FIGUEIREDO, P N. Technological learning and competitive performance. Cheltenham, UK and Northampton, MA, USA: Edward Elgar, 2001.

FLEURY, A.; FLEURY, M. T. L. Estratégias indústriariais e formação de competências: um quebra cabeça caleidoscópio da indústria brasileira. Ed. atlas 3a ed. São Paulo, 2006.

SWIERINGA, J; WIERDSMA, A. La organización que aprende. Wilmington: Addison- Wesley, 1995.

Yin, R. Case study research: design and methods (2nd. ed.). Londres: Sage. 1994. 


\section{Dados autores:}

Nome completo: Lucyanno Moreira Cardoso de Holanda

Universidade Tecnológica Federal do Paraná

Programa de Pós-graduação em Engenharia de Produção

Aluno Mestrado/Bolsista

Rua Coronel Dulcido, 612, Centro, Ponta Grossa - PR. CEP: 88010280

(42) 32234209 (42) 88181212

lucyanno@gmail.com

Nome completo: Neudi Luís Scandolara

Universidade Tecnológica Federal do Paraná

Programa de Pós-graduação em Engenharia de Produção

Aluno Mestrado

Rua Dr. Paula Xavier, 815. Ap. 02. Centro, Ponta Grossa, Paraná - PR, CEP: 84010270

(42) 32438257

neudi.scandolara@masisa.com

Nome completo: Antonio Carlos de Francisco

Programa de Pós-graduação em Engenharia de Produção

Professor/ pesquisador

Av. Monteiro Lobato, Km 04 - Sta. Monica. Ponta Grossa-Paraná. CEP: 84016-210

Fone/Fax : (042) 3220-4805

acfrancisco@gmail.com

Recebido para publicação em: 20/04/2009

Aceito para publicação em: 03/06/2009 